\title{
Description of the Process to Validate the Mexican Nurse Informatics Competency Self-Assessment Scale
}

\author{
Erika LOZADA-PEREZMITRE ${ }^{\mathrm{a}, 1}$, Erick LANDEROS-OLVERA ${ }^{\mathrm{a}}$, \\ Rosa Maria GALICIA-AGUILAR ${ }^{\mathrm{a}}$, Laura-Maria PELTONEN ${ }^{\mathrm{b}}$, \\ Raji NIBBER $^{\mathrm{c}}$, Adrienne LEWIS ${ }^{\mathrm{d}}$, Lorraine BLOCK ${ }^{\mathrm{e}}$, \\ Lisiane PRUINELLI ${ }^{\mathrm{f}}$, Charlene RONQUILLO ${ }^{\mathrm{g}}$ and Maxim TOPAZ $^{\mathrm{h}}$ \\ ${ }^{a}$ School of Nursing Benemerita Universidad Autonoma de Puebla, Mexico \\ ${ }^{\mathrm{b}}$ Department of Nursing Science at the University of Turku, Finland \\ ${ }^{\mathrm{c}}$ Cancer, Care, Fraser Health Authority, Canada, Canada \\ ${ }^{\mathrm{d}}$ University of Victoria, British Columbia, Canada \\ ${ }^{\mathrm{e}}$ School of Nursing, British Columbia, Canada \\ ${ }^{\mathrm{f}}$ School of Nursing, University of Minnesota, USA \\ ${ }^{\mathrm{g}}$ School of Nursing, University of British Columbia, Okanagan, Canada \\ ${ }^{\mathrm{h}}$ School of Nursing, Columbia University Data Science Institution, USA
}

\begin{abstract}
Nurses need to have sufficient competencies in nursing informatics to be able to provide safe and efficient care. The Self-Assessment of Nursing Informatics Competencies Scale (SANICS) has been developed and validated as a self-report measure of informatics competencies in Western settings. In this work, we describe the ongoing study that aims to validate and translate SANICS into the Mexican setting.
\end{abstract}

Keywords. Nursing Informatics, competencies, SANICS, psychometrics

\section{Introduction}

It is necessary for nurses to have the necessary skills to understand and apply technology to provide high-quality, accessible, efficient and safe care. Nursing informatics (NI) competency is defined as an acceptable level of knowledge, skills and ability to complete specific informatics tasks [1]. Studies show that there are factors that affect the development of NI competencies, such as knowledge about informatics and attitudes towards computers. The level of NI competencies can be assessed with validated scales and the results can be used to support the development and implementation of NI training programs for nurses [2].

Various scales have been developed to assess the level of NI competencies in the English language [3]. The Self-Assessment of Nursing Informatics Competencies Scale (SANICS) [4] has been demonstrated to have sound psychometric properties. SANICS is a potentially useful tool in the Mexican

${ }^{1}$ Corresponding Author, Erika Lozada-Perezmitre, School of Nursing, Benemerita Universidad Autonoma de Puebla, Mexico. 
nursing setting where say something about why you chose this tool specifically for the Mexican setting here. In this poster, an ongoing study that aims to translate and adapt SANICS to the Spanish language and the Mexican setting is described, with the aim of assessing the psychometric properties of this tool when used in the Mexican setting.

\section{Methods}

The translation, adaptation, and validation of SANICS into Spanish follows the guidelines described by Rodriguez [5]. It includes the following steps: 1) translation of the original instrument (SANICS) from English to Spanish, 2) an assessment of the translated Spanish version by experts in the field, 3) a pilot test and assessment of reliability [5] $(\mathrm{n}=30), 4)$ a pragmatic feasibility assessment and 5) an exploratory factor analysis. Approval to translate the instrument was obtained from the developer of the instrument. The study is currently ongoing (2019 to 2020).

\section{Conclusion}

Assessment of NI competencies has gained momentum around nursing. However, in Spanish speaking countries, there is a need for tools to measure NI competencies that are valid and reliable. Translating and validating a scale into Spanish and in the Mexican context would contribute to progress in identifying and addressing learning gaps [6], fostering the development of NI competencies.

\section{References}

[1] Hunter KM, McGonigle DM, Hebda TL. (2013) TIGER based measurement of nursing informatics competencies: The development and implementation of an online tool for Khezri and Abdekhoda 9 self- assessment. Journal of Nursing Education and Practice 3:70.

[2] Westra BL, Delaney CW. Informatics competencies for nursing and healthcare leaders. AMIA ... Annual Symposium proceedings. AMIA Symposium vol. 2008 804-8. 6 Nov. 2008.

[3] Jo M, Ha Y. Development and validation of an instrument to measure nursing information literacy competency. J Korean Acad Community Health Nurs. 2019 Mar; 30(1):25-37. https://doi.org/10.12799/jkachn.2019.30.1.25

[4] Yoon S, Yen PY, Bakken S. (2009). Psychometric properties of the self-assessment of nursing informatics competencies scale. Studies in health technology and informatics, 146, 546-550.

[5] Soriano RA. (2015). Diseño y validación de instrumentos de medición. Diá-Logos, (14), 19-40. https://doi.org/10.5377/dialogos.v0i14.2202

[6] Levy S. (2019). Commentary: Assessing nurses' informatics competency and identifying its related factors. Journal of Research in Nursing, 24(7), 539-540. https://doi.org/10.1177/1744987119839870 